Makale Gelis | Received: 12.11.2020

Makale Kabul | Accepted: 30.12.2020

DOI: $10.18795 /$ gumusmaviatlas.824988

Mavi Atlas, 9(1)2021: 316-325

Araştırma Makalesi | Research Article

\author{
Yasemin GÜRSOY \\ Dr. Öğr. Üyesi| Assist. Prof. Dr. \\ Trakya Üniversitesi, Edebiyat Fakültesi, Balkan Dilleri ve Edebiyatları Bölümü, Edirne-TÜRKIYY \\ Trakya University, Faculty of Letters, Department of Balkan Languages and Literatures, Edirne-TURKEY \\ ORCID: 0000-0003-2103-3410 \\ yasemingursoy@trakya.edu.tr
}

\title{
Yenilikçi Üretim Romanı Kıəıl Tanker Bağlamında Stahanovizm
}

Öz

Yeni bir düzen kurma politikası ile hareket eden Sovyet yönetimi, ilk günden itibaren ilerlemenin üretimle olacağının farkındadır. Bu amaçla her alanda üretim normları belirlemekte, sanayileşme ve üretimde yeni yöntemlerin bulunması için çalışanlarına maddi ve manevi desteklerde bulunmaktadır. İlk kez 1935 yılında Aleksey Stahanov tarafindan madencilik alanında yeni bir yöntem denenir ve üretim normları on dört kat aş1lır. Tüm ülkede duyulan bu rekor, Stahanov'un hayatını derinden etkilerken Sovyet tarihine de yeni bir terimin girmesine neden olur: Stahanovizm. 1930'lu yılların sonunda başlayan yeni yöntemler geliştirilerek normları aşma hareketine, ilk rekortmene ithafen, Stahanovizm, bu şekilde başarı kazanan kişilere ise Stahanovist denilmeye başlanır. Stahanovizmin, Sovyetler Birliği'nin her noktasına ulaşması adına tüm imkânlar kullanılmaktadır. Bunlardan biri de hiç kuşkusuz edebiyattır. Döneme hâkim olan sosyalist realizm akımı bu temayı işlemek adına oldukça uygunken yenilikçi üretim romanı ise konuyu ele almak için elverişli bir türdür. Belirtilen türde üretim ön planda tutulurken bu amaç için atılan ilk adımlar, yeni yöntemler arayan ve başarıya ulaşan alanında profesyonel mühendis, teknisyen, işçi gibi karakterler aracilığıly verilmektedir. Kendisi de mühendis olan ve edebiyatla uğraşan bir aileden gelen Yuri Krımov için yenilikçi üretim romanında eser vermek kendi biyografisini yazmak gibidir. Kı̨̨l Tanker romanı da yazarın 1935 yıllnda görev yaptığ1 gemideki tecrübelerinin bir sonucudur. Bu çalışmanın ilk bölümünde Aleksey Stahanov'un hayat hikâyesi ve Stahanovizmin ortaya çıkışı anlatılmaktadır. İkinci bölümde yenilikçi üretim romanı ele alınıp türün özellikleri detaylı olarak açılanmaktadır. Son bölümde ise Yuri Krımov’un yaşam öyküsüne kısaca değinilmekte, Kıə̨l Tanker romanı ise detaylı olarak incelenmektedir.

Anahtar Kelimeler: Stahanovizm, Yenilikçi Üretim Romanı, Yuri Krımov, Kızıl Tanker.

\section{Stahanovism in the Context of the Occupational novel The Tanker Derbent}

\section{Abstract}

The Soviet administration, acting with the policy of establishing a new order, is aware from the first day; progress will be based on production. For this purpose, it determines production norms in every field and provides financial and moral support to its employees in order to find new methods in industrialization and production. For the first time in 1935, a new method in the mining field was tried by Aleksey Stahanov and production norms were exceeded 14 times. This record, heard all over the country, deeply affected Stahanov's life and caused a new term to enter Soviet history: Stahanovism. New methods, which started in the late 1930s, were developed and the movement to exceed the norms, for the first record holder, was named Stahanovism, and those who succeed in this way were called Stahanovists. All possibilities are used for Stahanovism to reach every point of the Soviet Union. One of them is undoubtedly literature. While the socialist realism current dominating the period is quite suitable to handle this theme, the innovative occupational novel is a suitable genre to deal with the subject. While in the specified type production is prioritized, the steps taken for this purpose are given through characters such as professional engineers, technicians and workers who seek new methods and achieve success. For Yury Krymov, who is also an engineer and comes from a literary family, giving a work in an innovative occupational novel is like writing his own biography. The novel The Tanker Derbent is also a result of the author's experiences on the ship he served in 1935. In the first part of this study, the life of Aleksey Stahanov and the history of Stahanovism are explained. In the second chapter, innovative occupational novel is handled and the features of the genre are explained in detail. In the last part, Yury Krymov's life is briefly mentioned, and the novel The Tanker Derbent is examined in detail.

Keywords: Stahanovism, Occupational Novel, Yury Krymov, The Tanker Derbent. 


\title{
GÜRSOY, Yasemin (2021). "Yenilikçi Üretim Romanı Kız̨l Tanker Bağlamında Stahanovizm”, Mavi Atlas, 9(1): 316-325
}

\section{Giriş}

İnsanlık tarihinde yaşanan büyük olaylar, toplumda her alanı olduğu gibi edebiyatı da etkilemekte, genellikle yeni tür ve temaların ortaya çıkışı ile bu etki olumlu sonuçlanmaktadır. İktidarlar ve ideolojiler ise kimi zaman olumlu sonuçları kendi lehine kullanma yoluna giderler. $\mathrm{Bu}$ amaçla sanata ve sanatçılara müdahale ederler. Edebiyat profesörü İsmail Çetişli sanatçı ve ideoloji ilişkisine değinirken 1917 sonrası Rus edebiyatını örnek gösterir ve şunları ekler: İdeolojiler için sanat çok önemli ve öncelikli bir alanken bu alanın mimarı olan sanatçılar da diğer bireylerden daha fazla önem ve önceliğe sahip hale gelirler (Çetişli, 2017: 251). İdeolojiler, sanatçıların toplumu etkileme gücünden yararlanmak, onları kendi istek ve arzularına göre yönlendirmek için ellerinden geleni yaparlar.

Sovyetler Birliği’nde edebiyatın geleceğini ve gelişim sürecini belirleyen ilk adımlar 1905 yllında Vladimir Lenin tarafindan yayımlanan Parti Örgütü ve Parti Edebiyatı (Партийная организация и партийная митература) başlıklı makale ile belirlenir:

\begin{abstract}
Parti edebiyatının ilkesi nedir? Sosyalist proleter için edebiyat uğraşı sadece bir bireyin ya da grubun kazanç kapısı olamayacağı gibi aynı zamanda genel proleter davadan bağımsız tamamıla bireysel bir iş de olamaz. Kahrolsun partisiz edebiyatçılar! Kahrolsun üstinsan edebiyatçılar! Edebi uğraş, genel proleter davanın bir parçası, bütün işçi sınıfının tüm bilinçli öncüleri tarafindan harekete geçirilen tek büyük sosyal demokrat mekanizmanın çarkı ve dişlisi olmalıdır. Edebi uğraş organize, planlı, örgütlü sosyal demokrat partinin ayrılmaz bir parçası olmalıdır (Lenin, 1942: 7-8).
\end{abstract}

Yönetim sanat hayatını olduğu gibi aynı zamanda ülke içindeki çalışma ortamını da yakından takip etmekte, belirlenen üretim normlarını aşan kişileri ödüllendirmektedir. Normları ilk aşan olarak bu harekete adını veren Aleksey Stahanov, sanayileşme sürecindeki önemli bir isim haline gelir. Stahanov üzerinden yapılan propaganda kısa sürede yeni rekorların kırılmasını sağlar. $\mathrm{Bu}$ gelişmeyi parti lehine kullanan Josef Stalin, 1935 yllında düzenlenen I. Sovyetler Birliği Stahanovist Erkek ve Kadın İşçiler Zirvesi’nde yaptığı konuşmada Stahanovizm hareketinin işçilerin yaşamında yapılan iyileștirmelerden kaynaklandığına vurgu yapar ve Sovyet tarihine geçen sözlerini dile getirir: "Hayat artık daha iyi, yoldaşlar. Hayat artık daha keyifli. Eğer keyifli yaşanırsa, işler de yolunda gider" (Stalin, 1935: 368-369). Aleksey Stahanov sadece Sovyet tarihi değil, aynı zaman da edebiyat alanı için önemli bir figür olur. İdeoloji edebiyatı yönlendirirken ona belirli temalar da sunmaktadır. Bunlardan biri de Stahanov hareketidir.

Sovyet tarihi ve XX. yüzyll Rus edebiyatını ortak bir noktada birleştiren Stahanovizm ülkemizde özellikle edebiyat bağlamında araştırılmamıştır. Ayrıca konuyu ele almaya olanak sağlayan yenilikçi üretim romanı bir tür olarak bilinmemekte, hatta Türkçede terimin tam karş1lı̆̆1 bulunmamaktadır. Bu açıdan bakıldığında makalenin özellikle bu iki konu üzerine odaklanan başlıkları araştırmacılar için yeni çalışma alanları sunmaktadır. Yenilikçi üretim romanı türüne örnek olan Kıə̨l Tanker (Танкер “Аербент”) eserinin içerik ve üslup yönünden incelendiği son bölüm ise bir uygulama denemesi ile türün özelliklerini ve eserdeki Stahanovizm etkilerini ortaya çıkarmaktadır.

\section{Aleksey Stahanov ve Stahanovizmin Ortaya Çıkışı}

Aleksey Grigoryeviç Stahanov 3 Ocak 1906 tarihinde Rus İmparatorluğu'na bağlı Oryol'da dünyaya gelir. Çiftçilikle geçimini sağlayan aile, kıt kanaat geçinmektedir. Babanın savaşa gitmesinin ardından ise çok daha zor günler yaşarlar. Bu yıllarda genç Stahanov'un tek hayali bir at alıp tarımla uğraşmak ve iki kız kardeşi ile annesine bakmaktır, ancak yakınlarının art arda ölümünden sonra kendine yeni bir yol çizmek için yirmi bir yaşında Donbas'a madencilik yapmaya gider. Bu kararındaki en büyük etken, madencilerin çok kazandığını ve madenci olmak için fiziksel olarak 


\section{GÜRSOY, Yasemin (2021). "Yenilikçi Üretim Romanı Kız̨l Tanker Bağlamında Stahanovizm”, Mavi Atlas, 9(1): 316-325}

güçlü olunması gerektiğini duymasıdır. Çalışkanlığı ve azmi sayesinde madencilik işinde kısa sürede ilerleme kaydeder.

1935 yılı yazında her madenci için vardiya başına çıkarılması gereken kömür miktarı yedi buçuk ton olarak belirlenmiştir. Deneyimli bir madenci olan Stahanov ise o günlerde maden kazma işlemi sırasında bir iş bölümü yapılarak üretimin arttırılabileceğini fark eder. Stahanov'un planına göre bir kişi kömürü kırarken bir kısmı maden duvarlarını örer ve diğerleri atla kömürleri çekerse üretimi vardiyada seksen tona kadar çıkarmak mümkündür. Bu fikri madenin parti örgütü başkanı da onaylayınca Stahanov'un 30 Ağustos 1935 gecesi başlayıp bir sonraki gün biten vardiyası rekor denemesi olarak kaydedilir. Madende kendisiyle birlikte iki kişi daha çalışmakta, duvar örenler ve kömürü atlarla çekenler onlara yardım etmektedir. 5 saat 45 dakikalık vardiya sonunda ekip yüz iki ton kömür çıkarmayı başarır. Bu miktar devletin belirlediği üretim normunun on dört kat fazlasıdır. 2 Eylül günü Pravda dergisinde çıkan haberle tüm ülke bu rekoru öğrenir. Ancak gazetelerde bu başarının mimarı tek başına Aleksey Stahanov olarak lanse edilir. Haberlerde ne rekor günü için yapılan hazırlıklardan bahsedilir ne de Stahanov'un aynı vardiyada beraber çalıştıkları ve rekora birlikte imza attıkları ekip arkadaşlarının adları verilir (İsayeva, 2020: 372). Bu haberin etkisini fark eden Halk Komiserliği, maden bölgesinde Stahanov ve başarısını duyurarak yeni rekorların geleceğinin bilincindedir. Bekledikleri gibi 4 Eylül'de Miron Dyukayev tarafindan rekor, yüz on beş ton ile yeniden kırılır. 19 Eylül'de ise Stahanov liderliğindeki ekip, rekoru iki yüz yirmi yedi tona taşıyarak büyük bir fark açar.

Aleksey Stahanov gerçeği saklama gereği duymasa da rekoru tek başına kırdığ haberi hayatını derinden etkiler. 1935 yılında ünlü politika ve haber dergisi Time'in kapağında fotoğrafı basılır. Yeni çalışma sistemini geliştirmesi ve elde ettiği büyük başarıdan dolayı eğitim için Moskova'daki Endüstri Akademisine yollanır. 1937 yılında milletvekili olan genç madenci, Stalin tarafından sevilmekte ve desteklenmektedir. Ancak alkol sorunu yaşayan Stahanov, 1957 yllinda yönetimden uzaklaştırılır ve Donbas'taki bir maden işletmesinde görevlendirilir. Yıllar süren alkolizm ve madencilik geçmişinin etkileri ile akciğer ve kalp yetmezliği sonucunda 1977'de hayata gözlerini yumar. 1978 yılında ise rekor kırdığı şehir Kadiyevka'nın adı Stahanov olarak değiştirilir, dünya tarihinde ilk kez bir işçinin adı şehre verilerek onurlandırılmıştır (İsayeva, 2020: 374.) Günümüzde şehir hala rekortmen madencinin adını taşımaktadır.

Aleksey Stahanov'un başlattığı, eski yöntemleri sorgulama ve yenileri ile değiş̧tirme Sovyet yönetiminin hayalini kurduğu bir gelişmedir. İktidara geldikleri ilk günden beri eski olanı reddetme ve yeni bir düzen kurma prensibi ile politikalarını belirleyen Bolşeviklerin, maden ocaklarında başlayan bu hareketi desteklemesi ve tüm alanlara yayması öngörülebilir bir durumdur. Yönetimin özellikle maddi desteklerini gören çalışanlar, belirlenen ölçüleri geçmenin ve yeni rekorlar kırmanın yollarını ararlar. 1930’lu yılların sonunda başlayan yeni yöntemler geliştirilerek üretim normları aşma hareketine, ilk rekortmene ithafen, Stahanovizm, bu şekilde başarı kazanan kişilere ise Stahanovist denilmeye başlanır. Araştırmacı yazar Orhan Hançerlioğlu tarafindan hazırlanan Ekonomi Söəlïğï nde bu terim İngilizceden alıntılanarak verilmektedir: "Stakhanovculuk: (Os. Stakhanovizm, Fr. Stakhanovisme, Al. Stakhanovismus, tng. Stakhanovism) Önceden saptanan üretim ölçüsünü aşma... Normal üretim ölçülerini aşarak çalışan Stakhanov adındaki işçinin adından yapılmış bir deyimdir. Önceden saptanan çalışma ölçülerini aşan işçileri armağanlandıran ve aşamayanları da cezâlandıran çalışırma sistemi bu adla anılır” (Hançerlioğlu, 1993: 384).

Stahanov'un ardından tüm ülkede ardı ardına yeni rekorlar gelmeye başlar. Demirci Gorkovskiy, otomobil fabrikasındaki altı yüz yetmiş beş adet krank mili normunu, bin elli mille aşarak; dokumacı Vinogradov kız kardeşler on altı-yirmi dört tezgâh olan normu yetmiş-yüz, daha sonra ise yüz kırk dörde yükselterek; ayakkabı fabrikasında çalışan Smetanin üretimi iki katına çıkararak; makineci Krivonos yük trenini iki katı hızla kullanmayı başararak Stahanovizm 


\section{GÜRSOY, Yasemin (2021). "Yenilikçi Üretim Romanı Kız̨l Tanker Bağlamında Stahanovizm”, Mavi Atlas, 9(1): 316-325}

hareketinin öncü isimlerinden olurlar (Gruzitski, 2015: 42). Stahanovistler; ek ödemeler, ücretsiz ev, sinemaya sınırsız bilet gibi farklı şekillerde ödüllendirilir. Bu durum, işçilerin çalışma gayretini arttırır. Yönetimin de desteği ile kendi içinde bir yarışa giren işçi sınıfı eskiyi yenmek ve üretimi artırmak adına elinden gelini yapar. Bu sürecin tüm ülke geneline yayılabilmesi için ise her türlü yayın organı kullanılmaya çalışılır. Bunlardan biri de hiç kuşkusuz edebiyattır, hatta emeğin ve üretimin bireylerin önüne geçtiği bu dönem, kendi edebi türünün de doğuşuna zemin hazırlar.

\section{Sovyet Dönemi'nde Yenilikçi Üretim Roman1 ${ }^{1}$}

Stalin'in iktidara gelmesi ile her alanda yeni bir değişim dalgası başlar. Birinci Beş Yıllık Planın yürürlüğe girmesi, sanayileşmeye hız verilmesi ve kolektifleştirme hareketi ekonominin yeniden yapılanmasına sebebiyet verir. Bu değişiklikler demografik yapıyı da derinden etkiler. Yüzyıllardır değişmeyen Rus köy yaşam tarzının son bulması ile köyden kente büyük göçler gerçekleşir. Dün köyde çiftçilikle uğraşan insanlar artık işçi sınıfının üyesidir. Bu hızlı ve plansız göç dalgası şehirlerin de kültürel yapısını etkiler. Bu dönemde geleneksel Rus aydını da hem sanatsal hem de teknolojik bir baskı altına alınır (Dobrenko \& Tihanov, 2011: 146). Bu bask1 ile yeni bir yöntem belirleyen yazarlar yeni konu ve karakter arayışına girerler. Şehirdeki çalışma hayatı, üretim, sanayileşme gibi konularda çalışan yazarların en önemli karakterleri işçiler, teknisyenler, mühendislerdir. Belirtilen konu ve karakterler, yenilikçi üretim romanı (производственный роман) olarak adlandırılan türün Sovyetlerde de kendini göstermesine zemin hazırlar.

Gücünü işçiden alan bir toplumda emek ve üretimi merkezine koyan bu türün yükselişi de hızlı olur. 1920'li yılların ortalarından 1970’li yılların ortalarına kadar yaklassık elli yıllık dönemde etkisini gösterse de türün özelliklerini ortaya koymak özellikle XX. yüzyıl Rus edebiyatını daha iyi anlamak adına önem arz etmektedir. Araştırmacılar Natalya Moskovskaya ve Marina Matsayeva üretim romanı üzerine hazırladıkları detaylı çalışmada, türün natüralizm ile benzerliğine dikkat çeker ve iki tür arasındaki en önemli farkı ortaya koyar. Yenilikçi üretim edebiyatında da natüralizmde olduğu gibi eşya, makine, aracın fetiş hale getirilmesi söz konusudur, ancak bu noktada dikkat edilmesi gereken, yenilikçi üretim romanında insan tüm duyguları ve yaşanmışlıları ile ikinci plana itilmekteyken ana hedef her alandaki üretimin, sanayileşmenin ortaya çıkarılması ve bu süreç için gereken her unsurun ön planda tutulmasıdır (Moskovskaya \& Matsayeva, 2013: 284).

Moskovskaya ve Matsayeva’ya göre türün en belirgin özelliklerinden ilki, anlatının merkezine belirli bir ana karakterin konulmaması, bunun yerine üretimin gelişmesi ve ilerlemeyi sağlaması için alanında profesyonel olan olumlu karakterin bulunmasıdır. Karakter ahlaki bir ikilemde birakılır, bir tarafta kişisel bir problem olurken diğer tarafta işle, üretimle ilgili bir sorunu çözmesi gerekmektedir. Karakterin kişisel problem ile üretim sorunu arasında birakılması ve bir profesyonel olarak görevi tercih etmesi bu türün değişmez özellikleri arasındadır. Karakter, eser boyunca iniş çıkışlar yaşamaktadır. Kurgulanan karşıt karakterler aracılığıyla profesyonel olan ana karakter ile profesyonel olmayanlar karşı karşıya getirilerek okuyucuya üretimin önemi, onun için savaşanlar ve ona engel olanlar gösterilmeye çalış1lır. Kişi kadrosundan oluşturulan bir kolektif de yenilikçi üretim romanının önemli unsurları arasındadır. Özellikle kolektif ile ana karakterler ve karşıt karakterlerin ilişkileri üzerinden aktarılan olaylar, üretim sürecinin ilerleyişini ve bu süreçte karakterlerin tutumunu ortaya çıarması adına gereklidir (Moskovskaya \& Matsayeva, 2013: 285).

Yenilikçi üretim romanında olayın ortaya çıkışı, gelişimi ve doruk noktada yaşanan bunalım ile ele alınan üretim türünün farklı yönleri ortaya çıkarılır. Anlatıda önemli olan diğer bir nokta ise kullanılan mekândır. Üretim alanı fabrika, tersane, havaalanı, banka, hastane, şantiye gibi üretimin

\footnotetext{
${ }^{1}$ Rusçada производственный роман şeklinde geçen türün İngilizcesi occupational novel olmakla birlikte ilk kez Fransız yazar ve mühendis Pierre Hamp tarafindan 1920’li yıllarda kullanılmıştır. Türkçede henüz bilinen bir karş1lığ1 bulunmamaktadır. Bu nedenle türün içeriği dikkate alınarak yenilikẹci üretim romanı terimi tarafımızca oluşturulmuştur, tartışmaya ve yeni önerilere açıtır.
} 


\section{GÜRSOY, Yasemin (2021). "Yenilikçi Üretim Romanı Kız̨l Tanker Bağlamında Stahanovizm”, Mavi Atlas, 9(1): 316-325}

ve çalışmanın sürekli olarak devam ettiği bir ortamdır. Edebiyat profesörleri Naum Leyderman ve Mark Lipovetski’ye göre yenilikçi üretim romanında fabrika, işçilerin bir araya gelip bir şeyler ürettikleri toplum modelini resmeder (Leyderman \& Lipovetski, 2003: 273). Bu şekilde okuyucuya emeğin ve üretimin gücü aktarılırken fabrikadaki ilerleme ile toplumdaki arasında bir bağ kurulması sağlanir.

Yenilikçi üretim romanının bir tür olarak ayırıcı noktalarından biri, kuşkusuz kullanılan dildir. Esere konu olan üretim alanına göre belirlenen özel bir terminoloji kullanılmaktadır. Seçilen terimler, karakterlerin profesyonelliğini, anlatılanların gerçekçiliğini artırırken yazarın yeteneğine de bağlı olarak eserin okunmasını ve anlaşılmasını zorlaştırmaz. Özellikle mühendisliğin farklı alanları bu türe terminoloji açısından tükenmez bir kaynak sunmaktadır.

Türün önemli temalarından biri olan Stahanovizm ve onun farklı alanlardaki temsilcileri birçok yazar tarafindan işlenir. Panteleymon Romanov 1936 yllinda Novyy Mir dergisinde yayımlanan Yeni Insanlar (Новые АюАи) denemesinde işçi Stahanovistlerin yaşamını konu edinir. Sergey Kirsanov, 1950 yılında yayımladığı ve Stalin Ödülü aldığ1 eseri Makar Мazay (Макар Мазай) ile genç bir çelik işçisini ana karakter olarak seçer. Makar Mazay, gerçek yaşamdan seçilmiş bir karakterdir ve Stahanov hareketinin etkisi ile 6 saat 30 dakikada on beş ton çelik üreterek 1936'da büyük bir rekora imza atar. II. Dünya Savaşı'nın başlangıcında Almanlar tarafindan kurşuna dizildiğinde henüz otuz bir yaşında olan Makar, Stahanovizmin etkisi ile edebi bir eserde ölümsüzlük kazanır. Boris Gorbatov'un birkaç cilt olarak planladığı, ancak tamamlayamadığ1 eserinin ilk cildi Donbas (Аонбасc) 1951'de yayımlanır ve romanın ana temas1 1930'lu yillarda bu bölgede yaşanan Stahanov hareketidir. Bu temada eser veren yazarlardan biri de Yuri Krımov'dur.

\section{Yuri Krımov'un Kıəıl Tanker ${ }^{2}$ Romanında Stahanovizm}

Yuri Solomonoviç Krımov (1908-1941), yayınevi sahibi bir baba ile yazar bir annenin çocuğu olarak dünyaya gelir. Edebiyatla iç içe büyümesine ve yazarlık yeteneğine sahip olmasına karşın gençlik yıllarındaki sanayileşme hareketinin etkisi ile Moskova Devlet Üniversitesi Fizik Matematik Fakültesini bitiren Krımov, elektrik mühendisliği yapmaya başlar. 1934 yılında Hazar Denizi’ndeki bir tersanede görevlendirilir. Bu sayede deniz taşımacıllğı ile ilgili terimleri öğrenen yazar, eserlerinde özellikle tersanede çalıştığ dönemdeki tecrübelerinden yararlanır. 1938 yllında kendisine büyük ün kazandıran Kı̨̨ıl Tanker romanının yayımlanması yazarın hayatını değiştirir. $\mathrm{O}$ sırada Moskova Benzin Enstitüsünde bilimsel araştırmalar yürüten yazar, mesleğini yapmayı sürdürür. İki yıl sonra edebi işlerine zaman ayırabilmek adına mühendislik kariyerini noktalar. Ancak 1941 yılında gönüllü olarak katıldığı II. Dünya Savaşı, Yuri Krımov'un hayallerini tamamlamasına izin vermez. Girdiği bir çatışmada hayatını kaybeden yazar, ardında az sayıda eser bıraksa da yeteneği sayesinde edebiyat camiasında hala adından söz ettirmektedir.

Krımov'un mühendislik kariyeri ve Hazar Denizi’nde görev yaptığı Profintern tankerinde gördüğü Stahanovist çalışma sistemi ona dünyaca ün getiren Kıə̨ıl Tanker romanını yazması için kaynaklık eder. Farklı dillere de çevrilen eser, Krımov'un Yazarlar Birliği'ne alınmasını ve Kızıl Bayrak İşçi Nişanı ile ödüllendirilmesini sağlar. Yazarlar Birliği’ne kabul edildiği toplantıda editör Anna Karavayeva, romanın yakaladığı başarının sebebini açıklar: "Kı̨̆l Tanker romanını okurken Maksim Gorki'nin sözlerini hatırladım. Sovyet edebiyatı, emek teması coşkuyla yansıtılmadıkça yeterince duygusal ve anlamlı olamaz. Bu romanda emek teması oldukça derin ve etkili biçimde ele alınmıştır" (Libedinski, 1944: 14). Sosyalist realizm akımının en iyi örneklerinden olan Kı̨̨l Tanker, aynı zamanda kişi kadrosu, işlenen konu, anlatılan olaylar ve kullanılan dil ile yenilikçi üretim romanı olma özelliği taşımaktadır. Sekiz bölümden oluşan romanın ilk bölümünden sonra geriye dönüş

\footnotetext{
2 Eserin Rusçası Танкер “Аербент”” (Tanker Derbent) olarak geçmektedir. Çalışmamızda Levent Özübek tarafindan yapılan çeviriden yararlanılması ve Kı̨ıl Tanker şeklindeki çevirinin eserin içeriğini okuyucuya daha etkili aktarması nedeniyle başlık değiştirilmeden kullanılmaktadır.
} 


\section{GÜRSOY, Yasemin (2021). "Yenilikçi Üretim Romanı Kız̨l Tanker Bağlamında Stahanovizm”, Mavi Atlas, 9(1): 316-325}

tekniği ile o güne kadar yaşanılanlar anlatılmaktadır. Son iki bölümde ise olaylar ilk bölümle paralel götürülüp sonuca bağlanır. Bu teknikle yazar, ilk bölümünde romanı bitirmeden hemen önce yaşananları okuyucuya sunarak hem onların dikkatini çeker hem de sonucu saklı tutarak meraklarını kazanir.

Eserde olaylar, Hazar Denizyolları Telsiz İstasyonunda başlar. Ana karakter, yenilikçi mühendis Basov'un eşi Musya burada çalışmaktadır. Bir kutlama yemeğinde tanışan çift, kısa süre içinde evlenir. Tersanede çalışan Basov'un yenilikçi ve idealist yapısı üstlerini rahatsız eder ve onu Derbent tankerine görevlendirirler. Bu görevlendirme ise Musya ve Basov'un yollarını ayırmasına neden olur. Derbent'te de makinelerin daha iyi çalışması için elinden geleni yapan Basov'un fikirlerini, önce kabul etmek istemeseler de çoğunluğun onun arkasında durması ile tankerde büyük bir ilerleme kaydedilir. Bu ilerlemenin en büyük sebebi olarak Aleksey Stahanov'la ilgili haberin gemide öğrenilmesi gösterilebilir. Denizciler ünlü rekortmenden ve yenilikçi üretim modelinden oldukça etkilenirler. Öyle ki Hazar Denizi'nde görev yapan rakip Agamali tankeri ile üretim normlarını aşmak üzerine bir yarışa girerler. Her şey yolunda giderken Derbent Krasnovodsk'dan petrol almak için farklı bir rotaya yönlendirilir. İlk seferlerinde ise petrol yüklü Uzbekistan tankerini yedekleme görevi verilir. Tankerde petrol kaçağı olduğunu bilmelerine karşın kaptan ve seyir subayı durumu görmezden gelir ve yola çıkarlar. Sefer sırasında Uzbekistan gemisi yanmaya başlayınca seyir subayı Kasatski halatın kesilmesi emrini verir ve Uzbekistan tankeri çaresizliğe terk edilir. Durumu fark eden Guseyn sireni çalarak herkesi harekete geçirir. Yangının ortasına sandallarla giden denizciler diğer gemiden sağ kalanları kurtarırlar. Kahramanlar, yaralıları limana bıraktıktan sonra Agamali tankeri ile yarışlarına devam etmek için bir dakika bile beklemeden yeni sefere çıkarlar. Ayrıca Musya, ilk defa yangın olayından sonra Basov'u görmeye tankere gelir ve çift barışıp ilişkilerine devam etme kararı alır. Eser, Basov'un hem iş hem de özel hayatında kazandığı zafere vurgu yapilarak bitirilir.

Eserde geriye dönüş tekniği ile karakterlerin geçmişte yaşadıkları verilmekle birlikte Derbent tankerinde geçirdikleri süre yaklaşık yedi buçuk aydır. Aleksey Stahanov'la ilgili gazete haberini gemideyken aldıklarından olayların 1935 yılında yaşandığı sonucuna varılabilir. Mekân olarak ise iki yer ön plana çıkmaktadır. İlk olarak Basov'un limanda çalıştı̆̆ tersane kompleksi ki burada farklı bölümler ve birçok farklı iş kolunda çalışan bulunmaktadır. İkincisi ise eserin ana mekânı olana Derbent tankeridir. Derbent, kalabalık mürettebatı, karmaşık makine yapısı, motorları ve devasa büyüklüğü ile yenilikçi üretim romanı için uygun bir mekandır.

Kı̨ıl Tanker romanındaki Stahanov hareketinin mimarı hiç kuşkusuz ana karakter Basov'dur. Limanda çalıştığı dönemde işleri bekletmek istemeyen genç mühendis, "onarım bekletilmez (...) onarım işi aksamamalı" düşüncesi ile sürekli çalışan biri olarak resmedilir (Krımov, 2019: 39). İşçilerin ve teknisyenlerin çalışma prensiplerinin yeniden ele alınmasını öneren Basov, “yeni bir yöntemle personeli düzenlemenin bir yolunu” da bulur (Krımov, 2019: 41). İşleri o kadar başarılı bir şekilde yönetmektedir ki bu hem çalışanların hem de üstlerinin dikkatinden kaçmaz.

Basov'un limandaki ikinci önemli planı ise işçileri eğitmektir. Genç mühendis "takım tezgâhında çalışan bir işçinin, tıraşlama teorisini bilse, yaptığı işin ayrıntılarına neden gerek olduğunu bilse, işini kolaylıkla geliştirebileceğini düşünüyordu” (Krımov, 2019: 43). Bu planını üstlerine açıklayamadan Parti bölge komitesinden işçilerin eğitilmesine dair bir emir gelmesi, ana karakterin doğru yol üzerinde olduğunun göstergesidir. Isşçiler aldıkları eğitimlerle kendilerine güvenmekte, yeni yöntemler geliştirmektedir. Fabrikadaki tornacı Zakiriya Eybat, geliştirdiği bir yöntemle bir pistonu altı saat yerine iki buçuk saatte yapmayı başarır. Ancak Basov hariç, ustabaşı da yönetim de dâhil olmak üzere hiç kimsenin desteğini alamaz. Çalışma ortamında karşıt karakterler olarak Yakob Neuman ve Bronnikov gibi mühendisler yazar tarafından titizlikle kurgulanmıștır. Basov, yeni üretim modeli geliştiren tornacıyı onlara karşı korumaya çalışı "Yönetim paniğe uğradı çünkü 


\section{GÜRSOY, Yasemin (2021). "Yenilikçi Üretim Romanı Kız̨l Tanker Bağlamında Stahanovizm”, Mavi Atlas, 9(1): 316-325}

işçiler beyinlerini kullanmaya başladılar. Kusura bakma ama bu gericilik, ödleklik” (Krımov, 2019: 46) diyerek müdürü Yakob Neuman'a karşı çıkması anlatıda olayların gelişmesi için önemli bir noktadır. Basov yeniliği, ilerlemeyi, üretimi hızlandıracak her öneriye açıkken eskinin temsilcileri olarak kurgulanan Neuman ve Bronnikov gibi karakterler onu durdurmaya çalışır ve tornacının yeni yöntemini uygulamaya koymazlar.

"Tesisteki bu çirkin, zamanı geçmiş düzene, hep aynı hataların tekrarlandığı bu kaosa sımsıkı sarılmışlardı" diye düşünür Basov ve bu çalışma prensibinin doğru olmadığının bilincindedir (Krımov, 2019: 59). Attığı her yenilikçi adımın önünün kesilmesine, etrafindaki insanlar tarafindan dışlanmasına, çalışması karşılığında hak ettiği değeri maddi ve manevi açılardan görmemesine karşın genç mühendis bir profesyonel gibi davranmaktadır. İşini ve yenilikçi düzeni korumak adına elinden geleni yapar ancak bu durum üstlerinin artık canını sıkmaktadır. Bu nedenle Basov'un limandaki görevine son verilir ve üstleri tarafindan Derbent tankerine görevlendirilir.

Yenilikçi üretim romanının önemli bir temsilcisi olan ana karakter Basov, eserde ahlaki bir ikilemde de bırakılır. Gençlik yıllarından beri hayalinde canlandırdığı kadını gerçek yaşamda bulan ve onunla evlenen Basov, mutludur. Ancak eşi Musya bir yandan onu çok sevmekte diğer yandan ise onun herkes gibi olmamasindan dolayı endişe duymakta, onu garip, eksantrik bulmaktadır. Eşi ile aralarındaki bu sorunun çözülemeyeceği de romanda verilmektedir. Çünkü Musya, Basov’un üzerine ne kadar gitse de Basov bu sözlerine bir karşıllk vermemekte ve idealist yenilikçi yaklaşımından vazgeçmemektedir. Tankere görevlendirilmesi nedeniyle evine kimi zaman aylarca gelemeyecek, çok sevdiği eşini göremeyecektir. Özel hayatı ile görevi arasında tercih yapmak zorunda kalan ana karakter, bu ikilemde görevi seçecek kadar profesyonel davranır. Bu nedenle de Musya ile yollarını ayırırlar.

Sevdiği kadını ve yeni bir düzen kurmaya başladığı çalışma ortamını geride bırakan Basov’un Derbent tankerinde başaracakları ise tüm ülkede tanınmasına neden olacaktır. Derbent'in mürettebatı birbirlerinden kopuk, alakasız tipler olarak resmedilir hatta yazar onlanı anlattığ1 bölümün başlı̆ıını Ayaktakımı (СброА) olarak belirlemiştir. Kaptan Yevgeni Stepanoviç Kutasov ve Seyir subayı Kasatski devrim öncesi yılları temsil etmektedirler, ikisi de devrim yıllarında kendi hayatlarını kurtarmak için dostlarını yarı yolda bırakmışlardır. Derbentte bulunan kırk beş kişilik mürettebat, yenilikçi üretim romanının da özelliklerinden biri olan çalışanların oluşturduğu kolektif gruba uymaktadır: Lostromo Dogaylo, ikinci kaptan Alyavdin, kamarot Vera, Pompolit Bredis, beş Kızıl bahriyeli (yeni mezun Komsomol üyesi gençlerdir ve sürekli beraber hareket ederler, üçü elektrik teknisyeni, biri makinist, biri de mühendistir), telsizci Volodya, makinistler Kozov ve Gazaryan, tayfa Hrulev, Fomuşkin ve Kotelnikov, vd. Basov aralarında en sevilmeyen ve kabul görmeyen karakterdir. Ona göre tüm mürettebatın "hepsi gevşekti, hepsi anlaşılmaz şekilde birbirine benziyordu. Gayretleri sahte görünüyor, ciddi tavırları komik kaçıyordu” (Krımov, 2019: 77). Kaptan Yevgeni Stepanoviç ise döküntü, ayaktakımı, ayyass olarak tanımladığı ekibini yetersiz görmekte ve bu nedenle onlarla sefere giderken büyük bir kaygı duymaktadır. Onlardaki potansiyeli gören ve Basov'u buna ikna eden geminin politik lideri Bredis'tir. Sovyet iktidarı için cephede savaşmış olan Bredis, ülkenin kalkınma sürecinde de üretim savaşı verildiğini ve bu savaşta herkesin canını ortaya koyması gerektiğini vurgular: "Tüm güçleri ile çalışmaları için bunu kafalarına sokmalısın. Sonuçta senin makinistlerin kimdir? Kardeşlerin, işçiler, proleterler. Ayaktakımı değil" (Krımov, 2019: 84-85). Bu sözler, Basov’u derinden etkiler ve Stahanov seferini başlatırken çalışma arkadaşlarına güvenmesini sağlar.

Eserde ana karakter Basov olarak görülse de yenilikçi üretim romanının bir gereği olarak diğer karakterlerin de ön plana çıktığ anlar vardır. Rus yazar A. Platanov, bu türde eser veren yazarlar içinde Yuri Krımov'u ayrı bir yerde tutar ve onun Kı̨̋l Tanker'deki kişi kadrosunu kurgularken ortaya çıan sanatsal yeteneğine vurgu yapar (Platanov, 2005: 68). İkinci derece 


\title{
GÜRSOY, Yasemin (2021). "Yenilikçi Üretim Romanı Kız̨l Tanker Bağlamında Stahanovizm”, Mavi Atlas, 9(1): 316-325
}

karakterler anlatının kimi noktalarında Basov'un seviyesine kadar getirilir ve bu şekilde eserde yer alan her birey öncelikli ve gerekli olur. Romanda özellikle Guseyn karakteri eserin bazı noktalarında ana karakter olarak davranmakta, olaylar onun sayesinde yön değiştirmektedir. Firtına sırasında motorların üzerini kanvasla örterken neredeyse dalgalara kapılıp ölümden döner. Ancak görevi olmayan bir işi başarıyla tamamlayıp tankerin güvenliğini korumayı başarır. Özellikle yanan Uzbekistan tankeri için yapılan müdahale onun cesaretinin ve "Sovyet denizciler yoldaşlarını terk etmez" düşüncesinin ürünüdür (Krımov, 2019: 188). Mürettebatın anlatıldığ1 bölümde tankerden ayrılmak için bir çıkış yolu arayan Guseyn, Stahanov hareketinin başlaması ile değişir, limana geldikleri günlerde bile dişarı çıııp kız arkadaşını görmek yerine motor dairesinde çalısmaya devam eder. Diğer denizcilerde de aynı değişim görülmektedir. Stahanov hareketinin etkisi ile üretim normunu aşma hedefi, rakip tankerle yarışa girme fikri ve limanda kendilerinden Stahanovistler olarak bahsedilmesi mürettebatı bir araya getiren, gerçek bir kolektif gibi hareket etmelerini sağlayan güçlerdir.

Yazar, Stahanov hareketinin eserinde işlediği bölüme Stahanov Seferi (Стахановский Рейс) başlığını vererek okuyucunun dikkatini çeker. Eserin daha ilk bölümünde de Derbent için Kıそৃl Tanker, Stahanovcu Tanker benzetmeleri kullanılmaktadır. Bu bölümde Stahanov'un eski düzene karşı verdiği savaş anlatılmaktadır:

\begin{abstract}
Aleksey Stahanov eski teknik normlara inatla sarılmak isteyen bazı bürokrat kafalı yönetim yetkililerine karşı büyük ve zor bir mücadeleye katlanmak zorunda kalmıstı (...) modası geçmiş eski standartlarda inatla ayak direyen yöneticilere karşı zor ve uzun bir mücadele vermişti (...) korkak yöneticiler onu azarlamışlar, ustalar küçümsemişlerdi, "beceriksiz toy" demişlerdi ona (Krımov, 2019: 118-119).
\end{abstract}

Anlatılanlar, ana karakter Basov'un başından geçenlerle oldukça benzerdir. Basov da Stahanov gibi eski düzene bağlı üstlerine karşı büyük bir mücadele verir ve onlar tarafından kabul görmez. Yazar, Stahanov'u anlatırken okuyucunun Basov ile bir bağlantı kurmasını sağlar. Aslında herkese benzemeyen, eski düzeni sorgulayan genç mühendisin doğru yol üzerinde olduğu bir kez daha vurgulanmaktadır.

Stahanov'la ilgili haber tüm mürettebatı derinden etkiler. Bu haberden önce rakip tanker ile yarışa girmiş olmaları, onları daha da istekli hale getirir. Bir sezon için belirlenen üretim normundan yirmi beş bin ton daha fazlasını taşımak üzerine olan bu iddia, tüm mürettebatın birlik olmasını ve canla başla çalışmasını sağlarken ekibin kendine olan güvenini de artırır. "Üstlerindeki o uyuşukluk, atalet hali kaybolmuş gibiydi. Yerini birinin yaşamında ilk kez ciddi bir işe yüreğini koyması gibi, sabırsız ve coşkulu bir şevke bırakmışı şimdi” (Krımov, 2019: 99). Mürettebattaki herkes yaptığ1 işteki eksikleri görmeye çalışırken yeni yöntemler geliştirirler. Makinistler, motorların çalışma prensiplerini değiştirerek hızı arttırırken dümendeki sapmaları en aza indirmeye çalışan denizciler daha önce hiç kimsenin cesaret edemediği sı̆̆ sularda yeni bir rota belirlerler. Eski düzeni sorgulayarak attıkları her yeni adım onları başarıya daha da yaklaştırır. Ekim ayında Astrahan sahiline yüz bin ton mazot taşıyan Derbent, rakibi Agamali'yi geçmeyi başarır. Agamali de Stahanov seferi başlatarak aradaki farkı kapatmaya çalışır. Gemiler arası yarışmalar bir süre sonra alışkanlık haline gelir. "İyi prim, gazetelerde makaleler, bir geminin diğerlerine telsiz mesajları hep görülen şeylerden oldu. Makine dairelerinde acil iş diye bir şey kalmamıştı" (Krımov, 2019: 148). Yazar iki gemiyi öncelikle üretim normu üzerinden bir yarışa sokar, sonrasında Stahanov'la ilgili haberin mürettebata bildirildiği bölümü kaleme alır. Bu şekilde aslında Sovyet insanlarının her birinde Stahanov olma potansiyelinin ve çalışma isteğinin var olduğunu gösterir. Tankerde alışlagelmiş eski düzenin sona ermesi ve yeni düzenin kurulması ile işlerin yoluna girdiği, üretim normunun aşıldığ1 hatta acil iş diye bir şeyin kalmadığı özellikle vurgulanır. Bu durum, okuyucuya yeni düzenin bir zaferi olarak lanse edilir. 


\section{GÜRSOY, Yasemin (2021). "Yenilikçi Üretim Romanı Kız̨l Tanker Bağlamında Stahanovizm”, Mavi Atlas, 9(1): 316-325}

Kı̨ıl Tanker romanında kullanılan dilin, yenilikçi üretim romanına ait özellikler taşıdığı görülmektedir. Yazarın gemicilik ve mühendislik deneyimi, alana ait terimleri iyi bir şekilde bilmesini sağlar. Eserde geçen kasara, kanvas, uskur, serdümen, bocurgat, istralya, donkerman, draft, pupa, valf, mavna, lostromo, balast gibi sözcükler özellikle seçilir ve olayların bir profesyonel gözünden anlatıldığına okuyucuyu ikna eder. Aynı zamanda gemide ve tersanede yapılan tamiratlar ve üretim süreçleri ayrıntılı olarak anlatılarak farklı bir dünyanın kapıları açılır. Yenilikçi üretim romanında kullanılan terminolojik dil ülkedeki sanayileşmenin gösterilmesi, bu alanlara karşı insanların merakını uyandırmak ve üretim sürecine onları da çağırmak adına da önem taşımaktadır.

\section{Sonuç}

Sovyetler Birliği’nin küllerinden doğan bir topluluk olduğu düşünüldüğünde sanayileşme ve üretime verdiği önemin nedeni anlaşılmaktadır. Bu uğurda bütün çalışma alanlarında üretimi artırmak maksadıyla normlar belirlenmiş ve kimi zaman belirlenen normlar aşılmışır. İlk rekortmen olarak gösterilen Aleksey Stahanov, bir propaganda aracina dönüştürülüp maddi ve manevi kazanımları ön plana çıkarılarak tüm Sovyet vatandaşlarına örnek olarak sunulur. Bu örneğin geniş kitlelere ulaşması adına edebiyat önemli bir rol oynar. Özellikle de aynı dönemlerde ortaya çıkan yenilikçi üretim romanı, konuyu ele almak için oldukça uygun bir türdür.

Çalışmamızda incelediğimiz Kıฉ̨l Tanker romanı; Stahanov hareketinin kolektif bir grubu nasıl değiştirdiğini, onların içindeki çalışma azmini nasıl ortaya çıkardığını göstermesi açısından önemli bir örnektir. Yenilikçi üretim romanı olarak sınıflandırılan eserin mekân, kişi kadrosu, konu ve dil özellikleri bakımından yaptığımız inceleme, bu sınıflandırmanın doğruluğunu ispatlamaktadır. İdealist bir profesyonel olarak resmedilen genç mühendis Basov, herkes tarafından dışlanmış hatta eşi tarafindan bile kabul görmemiş olsa da üretimde yeni yöntemler geliştirmek amacıyla çalışmaya devam eder. Karşıt karakter olarak kurgulanan mühendisler Neuman ile Bronnikov, kaptan Yevgeni Stepanoviç ve seyir subayı Kasatski, Basov'u sevmemekle birlikte onun emeğini ve çalışma gayretini takdir etmez, hatta ona engel olmak için farklı yollar denerler. Teknisyen Guseyn, anlatının bazı bölümlerinde ana karakter olarak karşımıza çıkmakta ve olayların seyrini değiştirmektedir. Aynı zamanda hem limandaki tesislerde hem de Derbent tankerinde oluşturulan çalışma ekipleri türün gerektirdiği kolektif kişi kadrosuna da yer verilmektedir. Eserde kullanılan gemicilik ve mühendislik terimleri de türün dil özelliğine uymaktadır.

Görüldügü üzere Yuri Krımov'un romanında Stahanovizm temasını bu kadar gerçekçi aktarmasının, kurgulanan kişi kadrosu ve kullanılan terime dayalı dilin başarısının temel nedeni, Stahanov hareketinin başladığı dönemde Derbent'le aynı özelliklere sahip bir gemide mühendis olarak görev yapması ve otobiyografik unsurlardan faydalanmasıdır. Yenilikçi üretim romanı Kıə̨l Tanker eserini incelememiz sonucunda türün temel özelliklerine sahip olduğu ortaya çıkmaktadır. Aynı zamanda Kıə̧l Tanker romanı aracılığıyla yenilikçi üretim romanı türü ve Stahanovizmin XX. yüzyıl Rus edebiyatı açısından önemi ve belirtilen konuların daha detaylı araştırılması gerektiği anlaşılmaktadır. Hem yenilikçi üretim romanı türü hem de Stahanovizmle ilgili yapılan ilk incelemelerden biri olması nedeniyle bu çalışmanın, araştırmacılara yol göstereceği ve yeni konular sunarak alana katkı sağlayacağı düşünülmektedir.

\section{Kaynakça}

ÇETIŞLİ, İsmail (2017). Edebiyat Sanatı ve Bilimi, Ankara: Akçă̆ Yayınları.

DOBRENKO, Yevgeni \& Galin TİHANOV (2011). Istoriya Russkoy Literaturoy Kritiki, Moskova: İzdatelstvo Novoye Literaturnoye Obozreniye. $42-43$.

GRUZITSKI, Yuri (2015). "Stahanovsjoye Dvijeniye Radi İdei ili Zarplatı?”, Oktyabr, 10:

HANÇERLIOĞLU, Orhan (1993). Ekonomi Sö₹lüğ̈̈, İstanbul: Remzi Kitabevi. 
İSAYEVA, Sanita (2020). "İstoriçeskiy Portret Alekseya Stahanova", Voyna i Mir v Oteçestvennoy i Mirovoy Istorii Materiah Mejdunarodnoy Naucnoy Konferentsii, ss. 371-374, Sankt-Peterburg: Sankt-Peterburgskiy Gosudarstvennıy Universitet Promışlennıh Tehnologiy i Dizayna.

KRIMOV, Yuri (2019). Kıə̨l Tanker, çev. Levent Özübek, İstanbul: Yazılama Yayınevi.

LENIN, Vladimir (1942). Lenin o Literature, Moskova-Leningrad: İzdatelstvo Detgiz.

LEYDERMAN, Naum \& Mark LIPOVETSKI (2003). Sovremennaya Russkaya Literatura: 1950-1990-ye Godr, Tom 2, Moskova: Izzdatelstvo Akademiya.

LİBEDINSKİ, Yuri (1944). "O Yurii Krımove”, Povesti Yuriya Krmova, ss. 5-22, Moskova: İzdatelstvo Sovetski Pisatel.

MOSKOVSKAYA, Natalya \& Marina MATSAYEVA (2013). "K Voprosu o Janrovoy Spetsifike Proizvodstvennogo Romana (Na Materiale Proizvedeniy Artura Heyli)", Vestnik Celyabinskogo Gosudarstvennogo Pedagogiçeskogo Universiteta, 3: 282-291.

PLATONOV, Andrey (2005). Raz̧mısleniye Çitatelya, Münih: ImWerden Verlag.

STALIN, Josef (1935). "Reç Stalina İ. V.", Pervoye V sesoyužnoye Soveşaniye Raboçib i RabotnitsStahanovtsev, ss. 361-376, Moskva: İzdatelstvo Stenografiçeski Otçyot. 